\title{
Material Sputtering with a Multi-Ion Species Plasma Focused Ion Beam
}

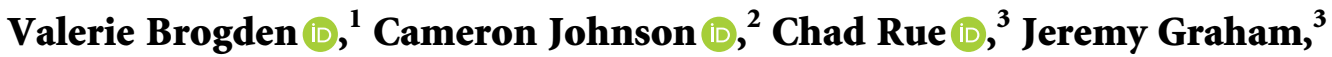 \\ Kurt Langworthy $\mathbb{D}^{1},{ }^{1}$ Stephen Golledge, ${ }^{1}$ and Ben McMorran $\mathbb{D}^{2}$ \\ ${ }^{1}$ CAMCOR-University of Oregon, 1443 E13th Ave, Eugene, OR 97403, USA \\ ${ }^{2}$ Department of Physics, University of Oregon, 1274 University of Oregon, Eugene, OR 97403, USA \\ ${ }^{3}$ ThermoFisher Scientific, 5350 NE Dawson Creek Drive, Hillsboro, OR 97124, USA
}

Correspondence should be addressed to Valerie Brogden; vbrogden@uoregon.edu

Received 23 September 2020; Revised 18 November 2020; Accepted 15 December 2020; Published 13 January 2021

Academic Editor: Guru P. Dinda

Copyright (c) 2021 Valerie Brogden et al. This is an open access article distributed under the Creative Commons Attribution License, which permits unrestricted use, distribution, and reproduction in any medium, provided the original work is properly cited.

\begin{abstract}
Focused ion beams are an essential tool for cross-sectional material analysis at the microscale, preparing TEM samples, and much more. New plasma ion sources allow for higher beam currents and options to use unconventional ion species, resulting in increased versatility over a broader range of substrate materials. In this paper, we present the results of a four-material study from five different ion species at varying beam energies. This, of course, is a small sampling of the enormous variety of potential specimen and ion species combinations. We show that milling rates and texturing artifacts are quite varied. Therefore, there is a need for a systematic exploration of how different ion species mill different materials. There is so much to be done that it should be a community effort. Here, we present a publicly available automation script used to both measure sputter rates and characterize texturing artifacts as well as a collaborative database to which anyone may contribute. We also put forth some ideas for new applications of focused ion beams with novel ion species.
\end{abstract}

\section{Introduction}

Plasma focused ion beam (PFIB) tools have revolutionized the scale of microstructural information that can be obtained about any kind of material specimen at the nanoscale. Compared to conventional liquid metal ion source (LMIS) $\mathrm{Ga}^{+}$FIBs, $\mathrm{Xe}^{+}$PFIB systems can operate at significantly higher beam currents, resulting in larger ion milling rates [1]. Until recently, only $\mathrm{Xe}^{+}$ion sources have been commercially available for plasma FIBs. However, $\mathrm{Xe}^{+}$is not necessarily the best ion species for milling all materials. For example, oxygen ion milling has been shown to reduce artifacts on biological tissue [2]. In addition, novel ion beam sources have enabled new optical applications in materials like diamond [3]. As FIB systems with novel ion sources become commercially available, entirely unknown application spaces are opening.
We have begun documenting applications of new ion beam sources with a ThermoFisher Helios Hydra. This tool is a multi-ion species PFIB, equipped with $\mathrm{O}^{+}, \mathrm{Ar}^{+}$, and $\mathrm{N}^{+}$ion sources alongside $\mathrm{Xe}^{+}$. The Hydra allows users to switch between these different ion sources in 10 minutes, enabling the use of specific beam chemistries for unique applications. In this paper, we present the results of an exploratory study to characterize the sputter rates and texturing artifacts created while milling four different substrates with the four ion beam species of the Helios Hydra PFIB and with $\mathrm{Ga}^{+}$on a Helios 600i LMIS FIB.

This experiment has been automated in a user-friendly script that can be run by anyone using a ThermoFisher FIB tool with the iFast Runner. The initial results are compiled in an online database and can serve as a look-up table for researchers who are interested in selecting the ideal ion source and beam energy for specific materials of interest. We invite the FIB community to collaborate on this project and 
use the aforementioned iFast script to share results from different combinations of substrates, energies, and ion species to the database [4].

\section{Methods}

In brief, the core of this experiment is to mill with known beam conditions for a given amount of time, take an image to qualify the smoothness of the mill, and then measure the volume removed. The substrates selected for the initial experiment were silicon, titanium, diamond, and LR White (an epoxy for fixing biological tissue). Each substrate was milled at four ion beam energies, using each of the five ion beam sources for a total of 20 data points per sample. The selected aperture, which defines the current for each beam energy, is listed in the table below. The nominal aperture values for current vary from one ion species to another. The script selects the closest available aperture to the specified current, which was established for $\mathrm{Xe}^{+}$.

Using an input form, the iFast script guides users through selecting an ion species and documenting the substrate milled. This information is saved and later written to file. Next, the script instructs users to insert a Faraday cup into the beam, and the beam current for each energy setting is measured and logged.

The user is given an option to perform a high-current, large-area, and glancing-angle milling step with stage rotation, referred to as a spin mill, to clean surface artifacts such as oxides and hydrocarbons. As a setup for this step, a circle of radius $500 \mu \mathrm{m}$ is milled with the stage at tilt $52^{\circ}$ (normal incidence to the ion beam). The stage then tilts to $-10^{\circ}$ to allow milling at a glancing angle. At this position, the script enters a repeat-loop which asks the user to find and center the circle with a stage move, performs live imaging with the FIB at $1 \mu \mathrm{A}$ for 5 seconds, rotates the stage by $37^{\circ}$, and then repeats the previous steps 12 times to ensure thorough coverage. Figure 1 shows a resulting surface after spin milling.

For some samples, such as LR White, the spin-mill step is not appropriate because it has been shown to create texturing artifacts rather than smoothing the substrate surface.

Next, the script instructs the user to move the stage to the center of the spin-milled circle and then mills an array of rectangles at each of the specified beam conditions for a user-defined length of time. After the rectangles have been milled, the script guides the user through milling a line across each of the rectangles, which is used as a depth reference mark. The script then records an SEM image and asks the user to measure the depth of each rectangle with a measurement tool with "cross-section correction" turned on. An example image of this measurement is shown in Figure 2. Finally, the recipe writes to file all pertinent information for each measurement, including sputter time, volume removed, and measured current. The data and images are saved into files sorted by the substrate and ion species type.

In some cases, the sputter rate is not spatially constant, resulting in a textured surface in the milled region. Consequently, the rectangular cross-section measurement technique cannot be applied at just one point to measure total sputter yields. The sputter yield measurements in this study were taken at multiple points in order to give an estimate of the variation in mill depth as well as measurement error. We place 20 evenly spaced points along the depth reference mark both in and outside the milled region. We measure the mean and standard deviation of the crosssection depth for the two different sets of points. The mill depth is then the difference of the two means, and the associated error is the two standard deviations added in quadrature.

\section{Results and Discussion}

For each substrate material, we generated a plot comparing the sputter yield of each ion species at the four different energies tested. Sputter yield is defined as the volumetric yield per dose where the dose is the measured current multiplied by the time spent milling.

3.1. Silicon. A plot of the sputter yield of silicon milled with different ion species at varying energies is shown in Figure 3. On silicon, the sputter yield was observed to vary significantly between ion species, with $\mathrm{Xe}^{+}$milling at the fastest rate. For $\mathrm{Xe}^{+}$, we observe the sputter yield steadily increasing as we increase the beam energy. However, the sputter rates of some of the other species peak at low energy and then flatten out as ion beam energy increases.

The peak in sputter yield that occurs at low energy for both nitrogen and oxygen raises some questions. Specifically, we were curious if the ions implanted during milling were changing the chemistry of the substrate material, hardening the substrate, and making it more difficult to mill at higher beam energies.

To investigate what chemical species are formed during milling and their depth distribution, we milled two $500 \mu \mathrm{m}$ squares into silicon using nitrogen ions at $5 \mathrm{kV}$ and $30 \mathrm{kV}$. An XPS depth profile was performed to determine the bonding environment at and near the milled surface. We also determined the nitrogen depth distribution via a ToFSIMS depth profile.

The N1s photoelectron spectra from the region milled with $\mathrm{N}$ at $5 \mathrm{kV}$ show a peak at $397.7 \mathrm{eV}$, the characteristic peak position for nitrogen in silicon nitride [5]. A representative N1s spectrum, obtained after a $90 \mathrm{~s}$ sputter with $\mathrm{Ar}+(3 \mathrm{kV}, 2 \mu \mathrm{A})$, is shown in Figure 4 . The binding energy scale was calibrated by setting the $\mathrm{Si} 2 \mathrm{p} 3 / 2$ peak to $99.3 \mathrm{eV}$. We can, therefore, confirm that milling silicon with nitrogen creates silicon nitride in the outermost few nm of the milled surface.

Nitrogen distribution was determined from ToF-SIMS depth profiles shown in Figure 5. The depth profiles were acquired in the usual "dual-beam" mode, employing a $2 \mathrm{kV}$ $\mathrm{Cs}+$ beam for sputtering, and a $25 \mathrm{kV} \mathrm{Bi3}+$ primary ion beam for the acquisition of the mass spectra.

The ToF profiles show that the relationship between beam energy and implantation depth for $\mathrm{N}^{+}$on a silicon substrate is $\sim 1 \mathrm{~nm} / \mathrm{kV}$. That value is notable because it 


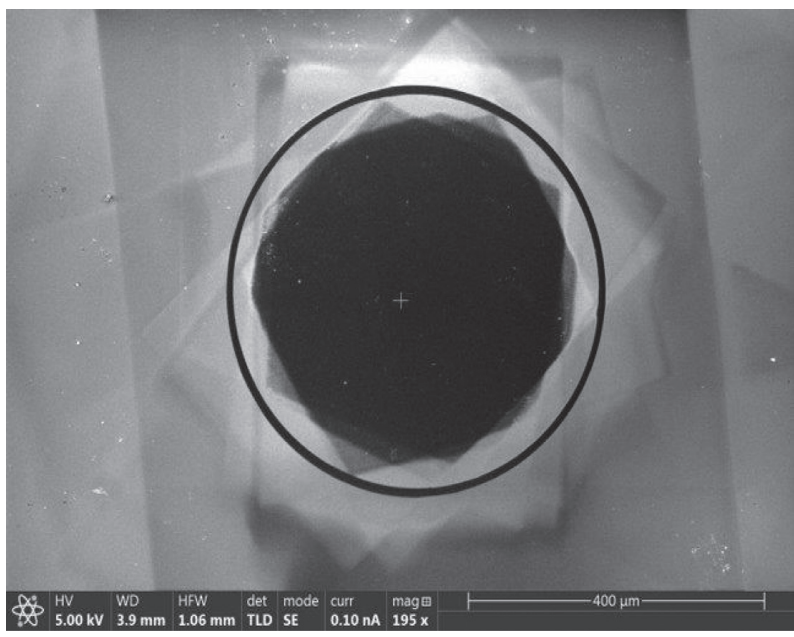

FiguRE 1: SEM image of silicon substrate after spin-mill processing for oxide and debris removal.

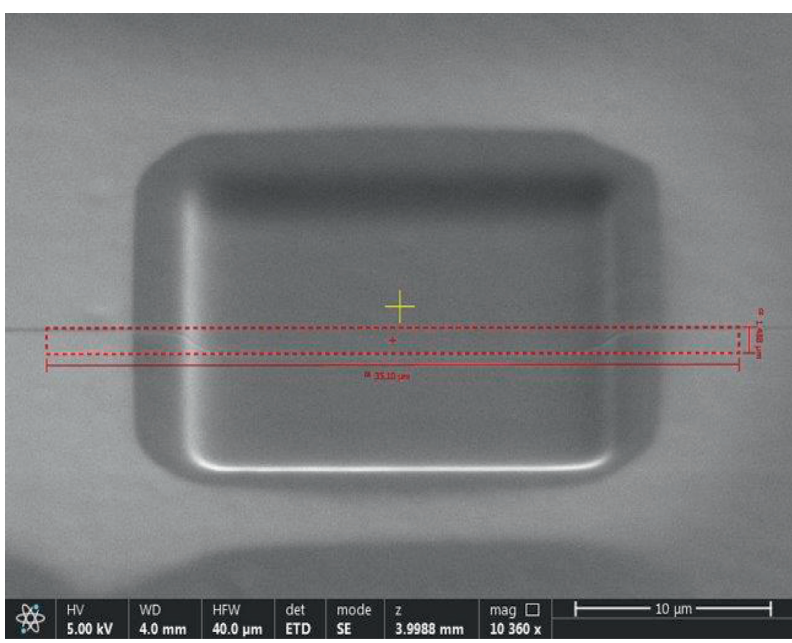

FiguRE 2: Depth measurement of a milled rectangle using the milled scribe line reference.

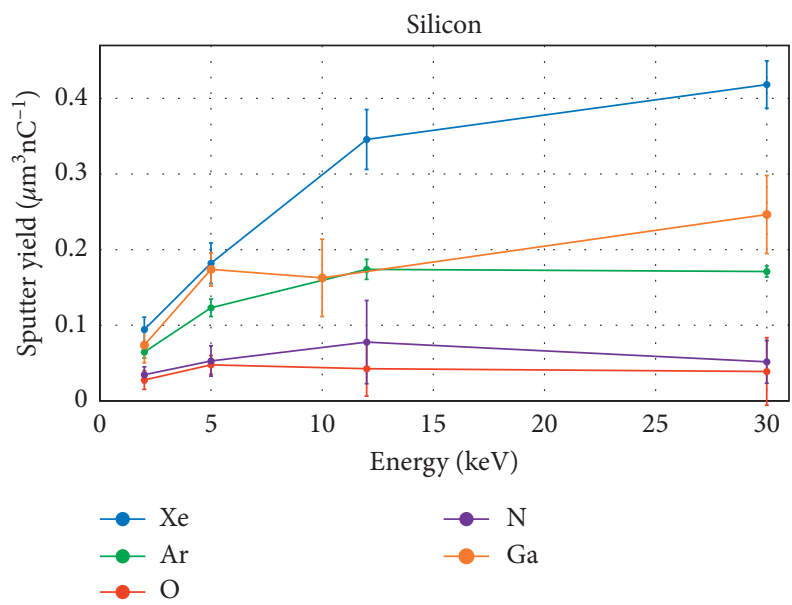

FigURE 3: Sputter yield of silicon milled with different ion species at varying energies. 


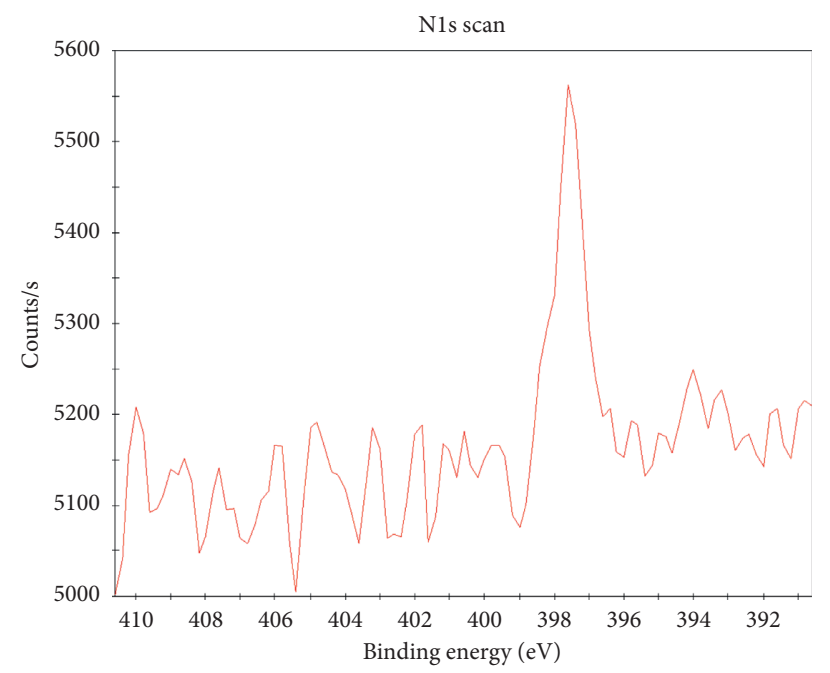

Figure 4: XPS N1s spectrum from surface of silicon coupon milled with $\mathrm{N}^{+}$at $5 \mathrm{kV}$.

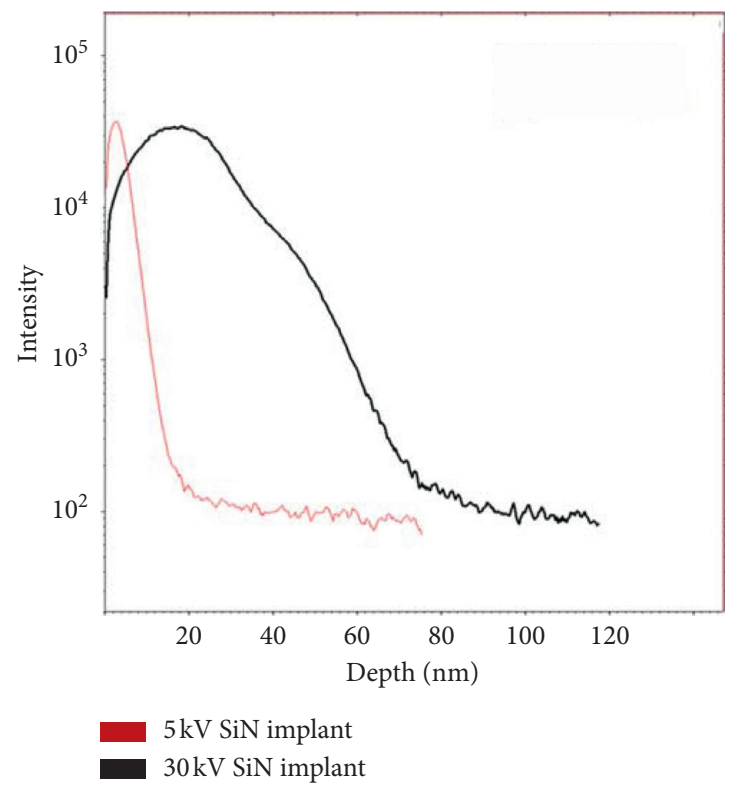

FIgURE 5: TOF SIMS data of the silicon region milled with $\mathrm{N}^{+}$at $5 \mathrm{kV}$ and $30 \mathrm{kV}$.

corresponds to the energy-to-damage layer approximation that is commonly used to model $\mathrm{Ga}^{+}$implantation in silicon, e.g., when preparing lift-out samples for TEM analysis [6].

To confirm that we are in fact changing the hardness of the silicon by creating $\mathrm{SiN}$ species, more investigation is necessary. For example, further studies should include testing the hardness of the silicon before and after nitrogen milling with a nanoindenter. If the hardness is changing, perhaps it is possible to utilize the formation of SiN species to an advantage. One could imagine milling with $\mathrm{N}^{+}$or $\mathrm{O}^{+}$to create etch masks, protective caps, or other uses for selective hardening of silicon.

To test the application of $\mathrm{O}^{+}$milling as an etch mask, $\mathrm{O}^{+}$ was implanted into silicon with a range of doses to alter chemical reactivity. After $\mathrm{O}^{+}$implantation, the sample was exposed to $\mathrm{XeF} 2$ gas, which attacks the native silicon. In
Figure 6 , note that the regions implanted with more $\mathrm{O}^{+}$ resisted the chemical attack, whereas lightly-implanted and nonimplanted regions were etched.

3.2. Titanium. It is generally thought that $\mathrm{Xe}^{+}$has the fastest sputter yield for most materials. However, as shown in Figure 7 , titanium is one substrate for which gallium is the superior ion species for rapid material removal at $30 \mathrm{kV}$.

Complex texturing artifacts are created when milling titanium with $\mathrm{O}^{+}$. We found that $\mathrm{O}^{+}$milling forms a unique swirling pattern which seems to nucleate around scratches on the substrate as shown in Figure 8.

It is clear that a chemical reaction is taking place on the surface during milling that is not fully understood. Further studies will include characterizing these features chemically using ToF SIMS. 


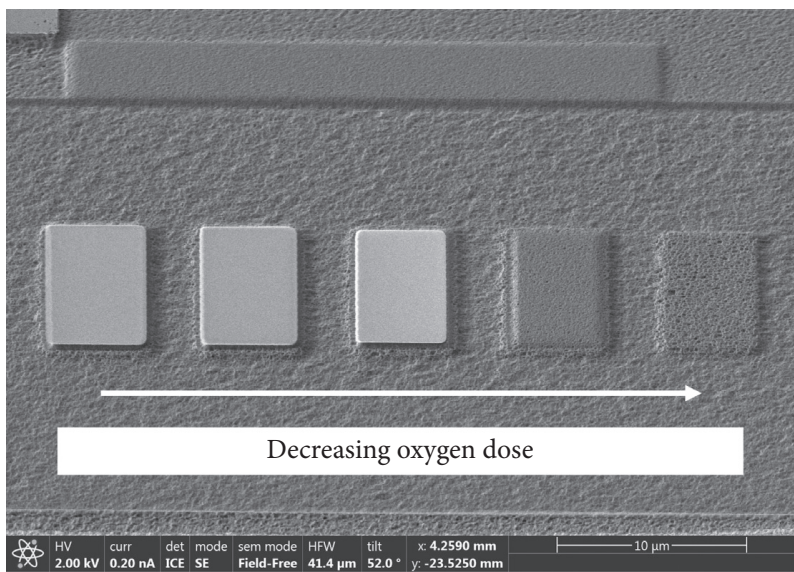

Figure 6: An array of $\mathrm{O}^{+}$implanted regions after the entire region was exposed to $\mathrm{XeF}_{2}$. Higher $\mathrm{O}^{+}$doses are on the left and lower doses on the right.

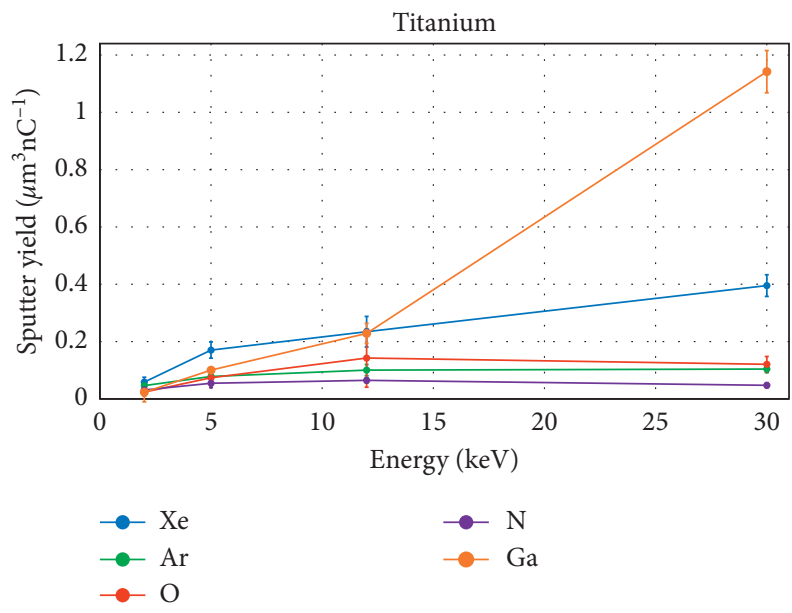

FIGURE 7: Sputter yield of titanium milled with different ion species at varying energies.

3.3. Diamond. Images collected at CAMCOR and ThermoFisher have shown that oxygen is a superior species for producing artifact-free cut faces on carbon-based substrates such as polymers, biological tissue, and diamond. Figures 9 and 10 show comparisons between $\mathrm{Xe}^{+}$and $\mathrm{O}^{+}$cuts on biological tissue and diamond.

As shown in Figure 11, the sputter yield on the diamond is higher with $\mathrm{O}^{+}$than with most other species, except $\mathrm{Xe}^{+}$and $\mathrm{Ga}^{+}$at $30 \mathrm{kV}$. In addition, while the other milling species show a drop-off in sputtering efficiency at lower energies, the change in yield for $\mathrm{O}^{+}$is not strictly decreasing. In fact, sputter yield for $\mathrm{O}^{+}$seems to level out as the beam energy decreases. We speculate that $\mathrm{O}^{+}$ combines with the carbon in the substrate to form volatile $\mathrm{CO}$ and/or $\mathrm{CO}_{2}$ species, so there is a chemical removal mechanism in addition to the mechanical sputtering component. This chemical volatilization is active even at lower beam energies. This speculation is supported by the findings of Refke et al. [7].

3.4. LR White. Initial attempts to recover depth profile results from the LR White sample were inconclusive for most ion species due to extreme texturing introduced during the milling process. We are re-evaluating our experimental approach at depth profiling for future attempts.

For texturing results, we note that nitrogen milling at $30 \mathrm{kV}$ appears to create the smoothest and most artifact-free finish when compared to the other species (Figure 12), many of which create dramatic pillaring artifacts (Figure 13).

For the reader's convenience, Figures 14-17 shown contain all images collected on each sample after milling with every ion species during our depth profiling experiment. This is simply for comparing texturing artifacts at a glance. Full-resolution images can be found in the FIB mill database [4]. 


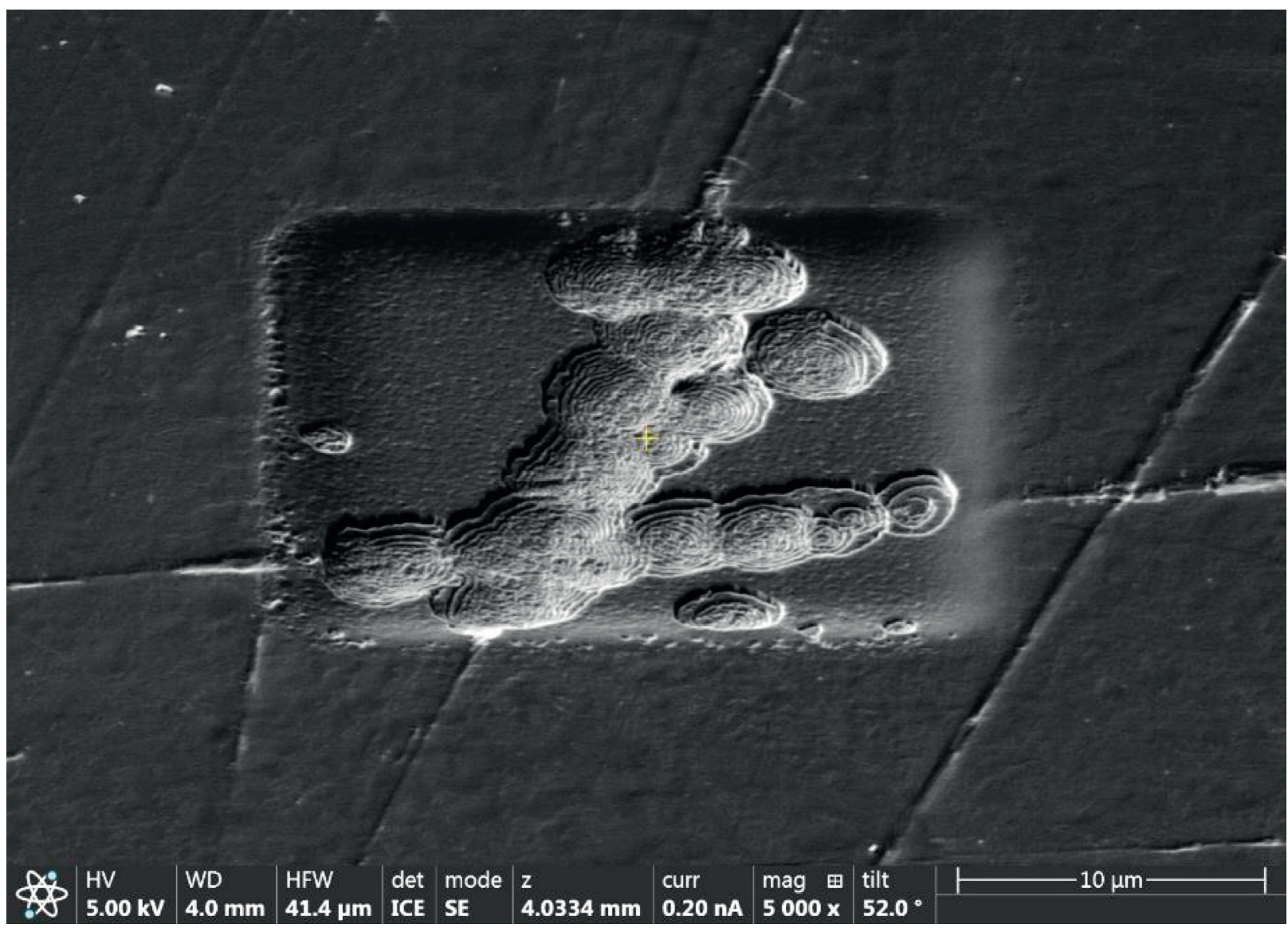

FIgURE 8: Titanium milled with $\mathrm{O}^{+}$at $30 \mathrm{kV}$.

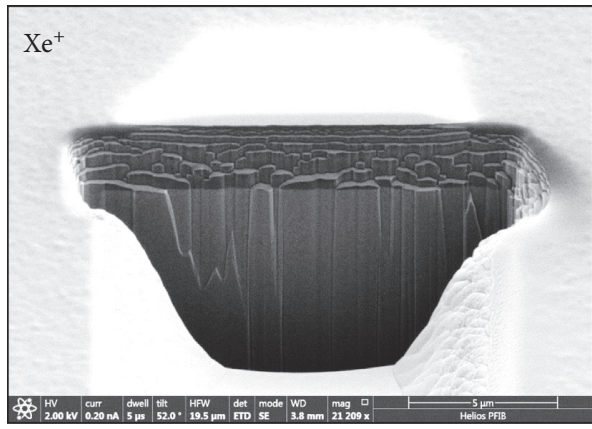

(a)

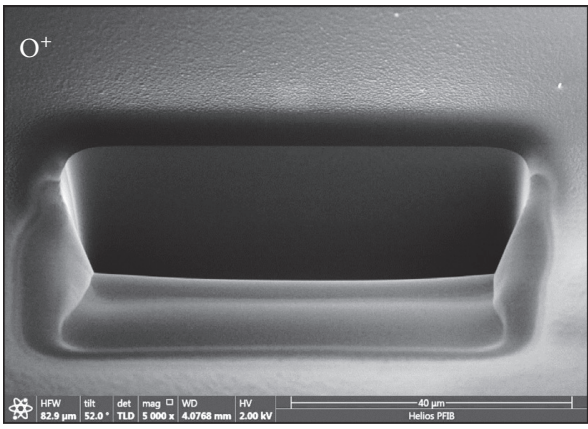

(b)

Figure 9: Example of superior cross-sectioning performance of $\mathrm{O}^{+}$vs. $\mathrm{Xe}^{+}$on diamond-like carbon.

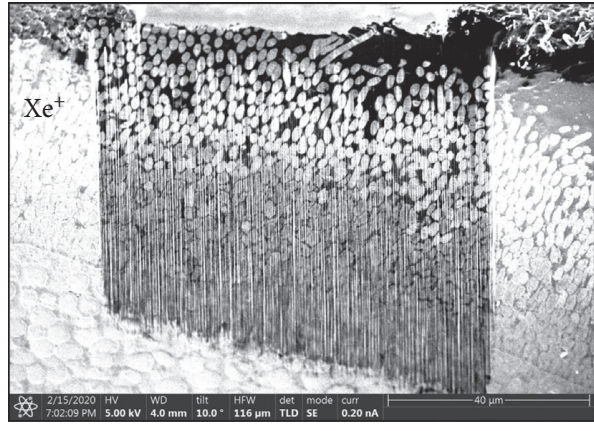

(a)

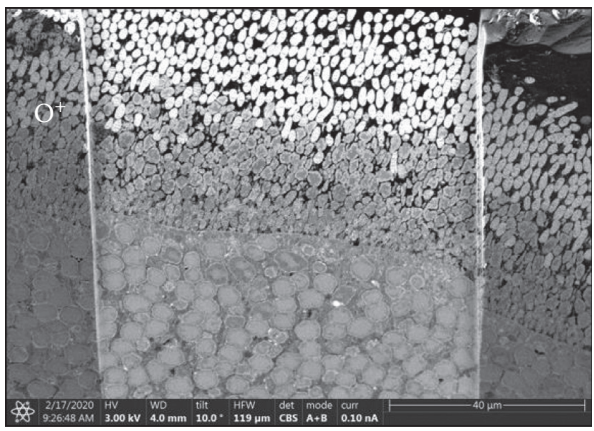

(b)

Figure 10: Example of superior cross-sectioning performance of $\mathrm{O}^{+}$vs. $\mathrm{Xe}^{+}$on biological tissue. 


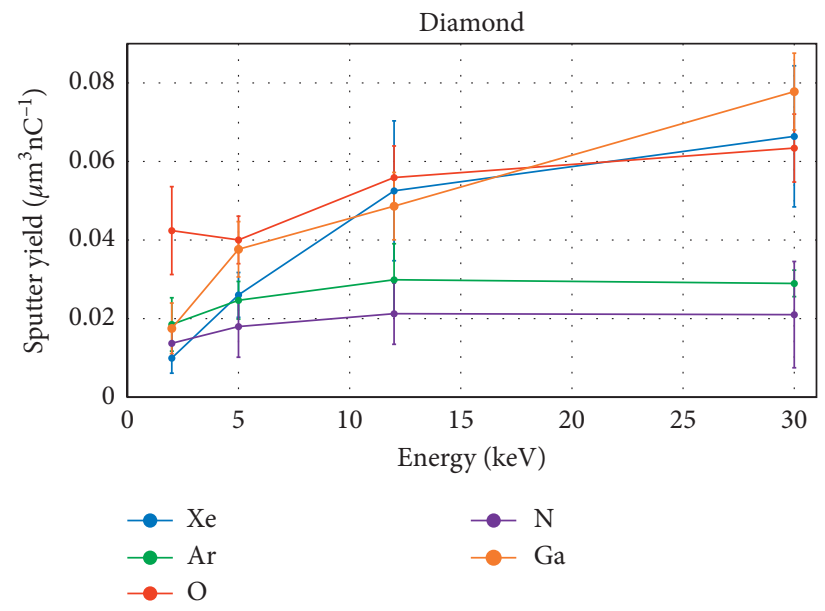

FIGURE 11: Sputter yield of diamond milled with different ion species at varying energies.

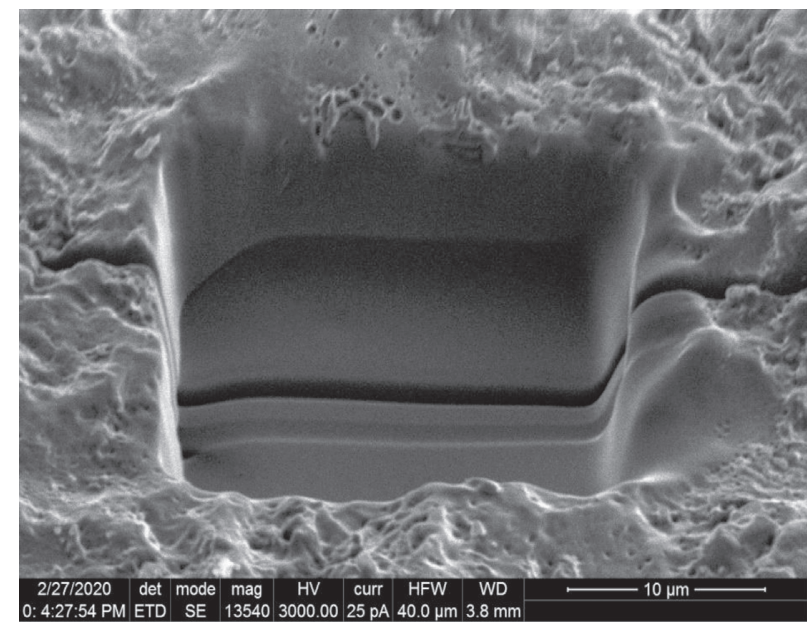

FIgURe 12: LR White milled with $\mathrm{N}^{+}$at $30 \mathrm{kV}$.

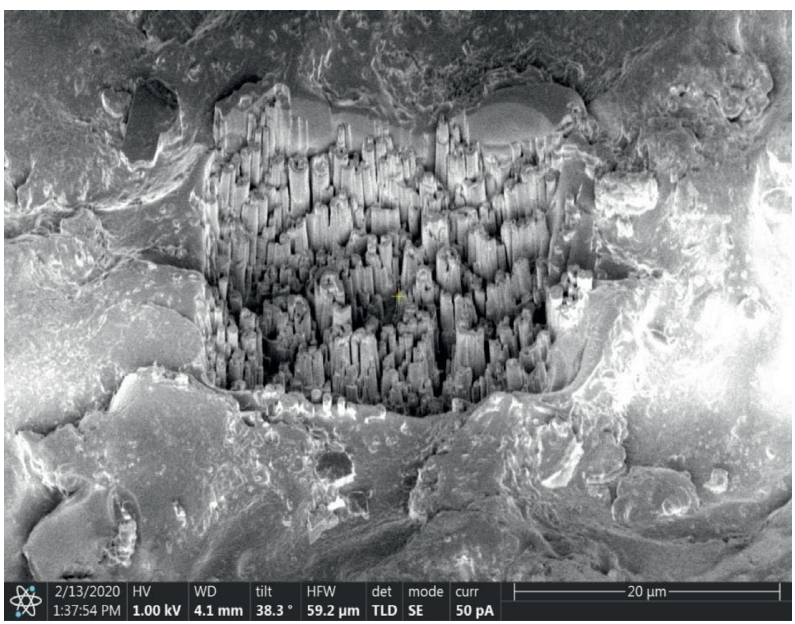

FIGURE 13: LR White milled with $\mathrm{Xe}^{+}$at $12 \mathrm{kV}$. 


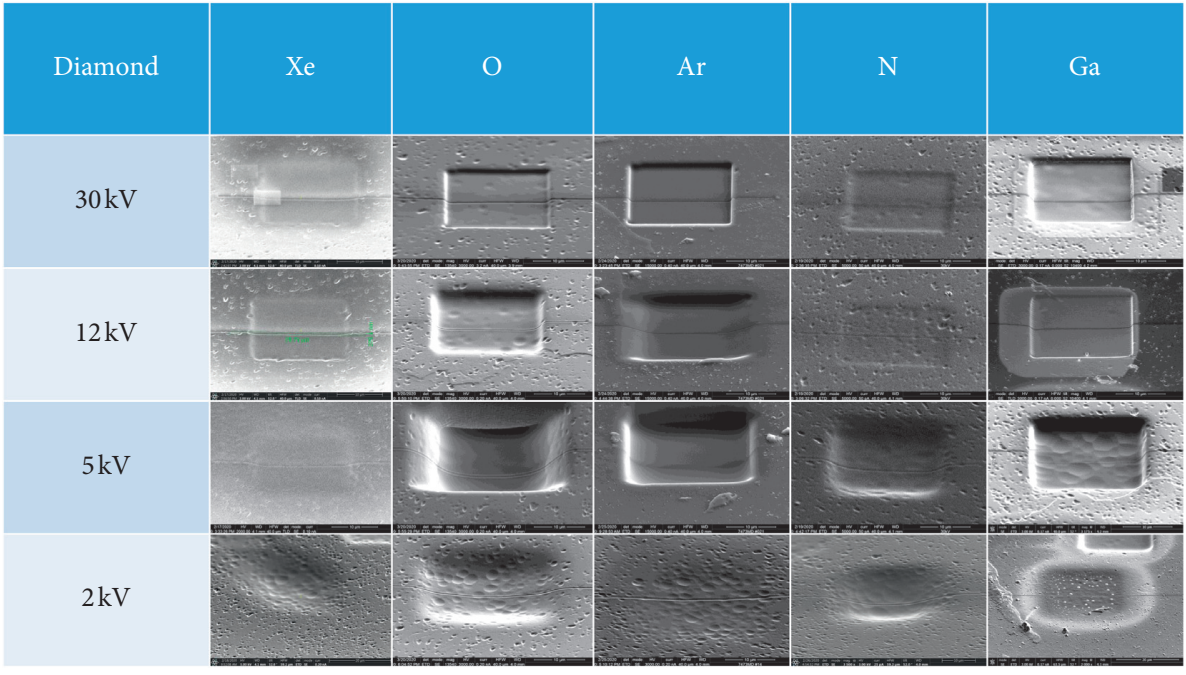

Figure 14: All images of diamond milled with different ion species at varying energies. Area is held constant at $20 \mu \mathrm{m}^{2}$. For beam current values, refer Table 1. All images were captured with a horizontal field width of $41.4 \mu \mathrm{m}$.

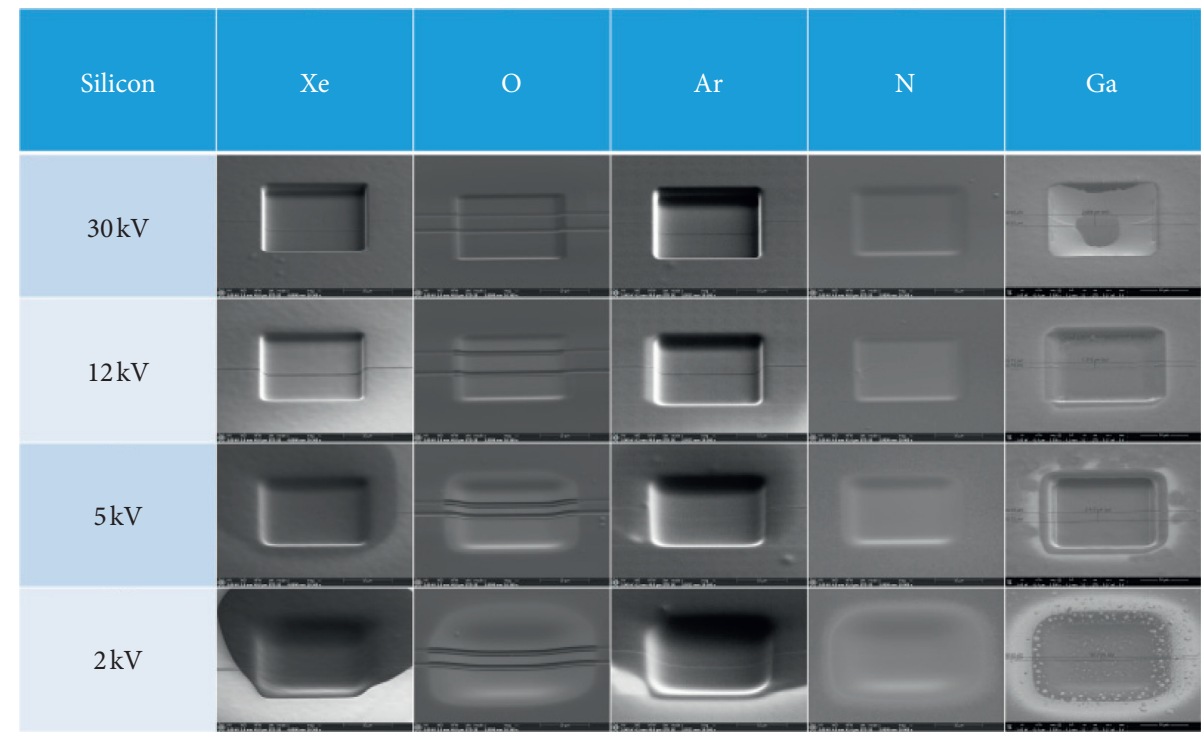

Figure 15: All images of silicon milled with different ion species at varying energies. Area is held constant at $20 \mu \mathrm{m}^{2}$. For beam current values, refer Table 1. All images were captured with a horizontal field width of $41.4 \mu \mathrm{m}$.

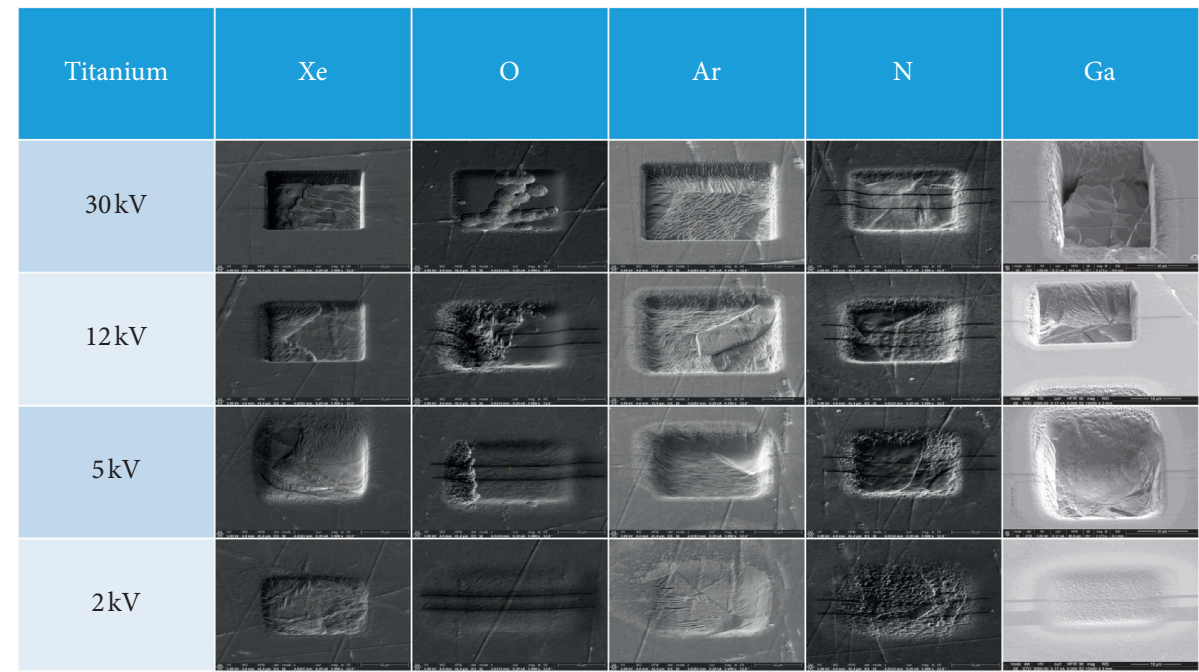

Figure 16: All images of titanium milled with different ion species at varying energies. Area is held constant at $20 \mu \mathrm{m}^{2}$. For beam current values, refer Table 1. All images were captured with a horizontal field width of $41.4 \mu \mathrm{m}$. 


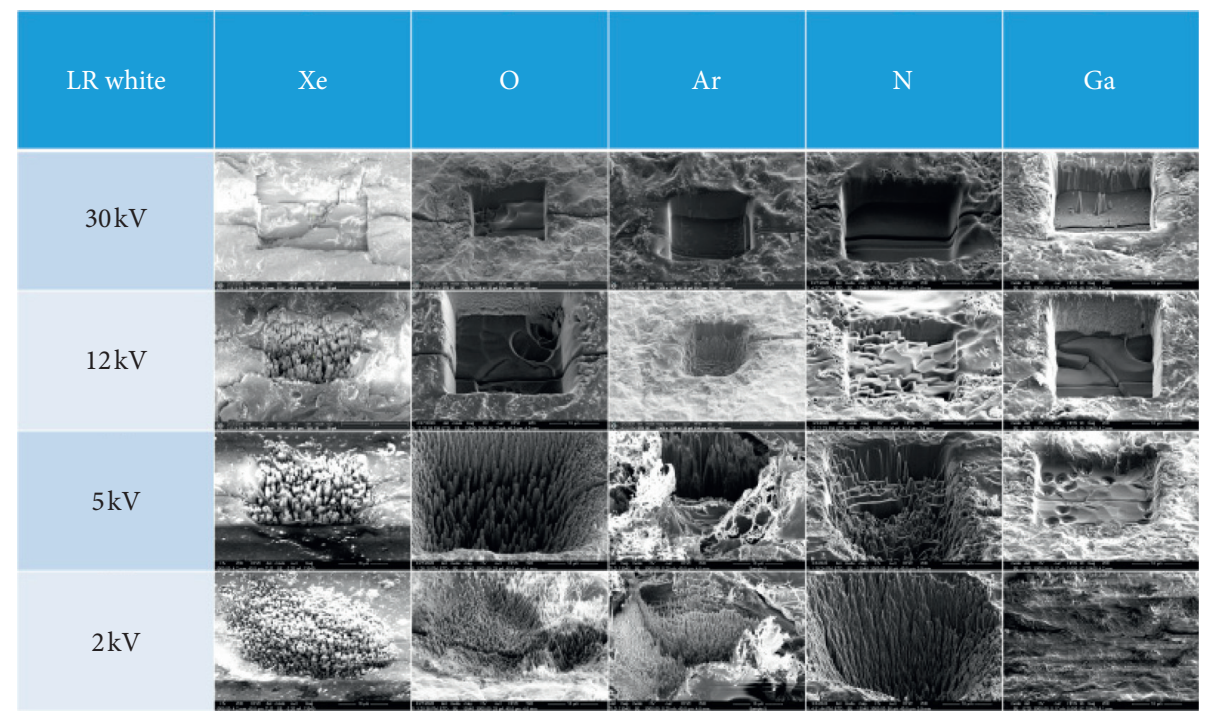

FIgURE 17: All images of LR White milled with different ion species at varying energies. Area is held constant at $20 \mu \mathrm{m}^{2}$. For beam current values, refer Table 1. All images were captured with a horizontal field width of $41.4 \mu \mathrm{m}$.

TABle 1: All aperture settings used in this experiment.

\begin{tabular}{lccccc}
\hline $\begin{array}{l}\text { Voltage } \\
(\mathrm{kV})\end{array}$ & $\begin{array}{c}\mathrm{Xe}^{+} \\
\text {current } \\
(\mathrm{nA})\end{array}$ & $\begin{array}{c}\mathrm{N}^{+} \\
\text {current } \\
(\mathrm{nA})\end{array}$ & $\begin{array}{c}\mathrm{Ar}^{+} \\
\text {current } \\
(\mathrm{nA})\end{array}$ & $\begin{array}{c}\mathrm{O}^{+} \\
\text {current } \\
(\mathrm{nA})\end{array}$ & $\begin{array}{c}\mathrm{Ga}^{+} \\
\text {current } \\
(\mathrm{nA})\end{array}$ \\
\hline 30 & 15 & 23 & 7.6 & 5.6 & 21 \\
12 & 20 & 6.9 & 14 & 13 & 18 \\
5 & 20 & 14 & 19 & 24 & 13 \\
2 & 12 & 15 & 3.1 & 3.8 & 7 \\
\hline
\end{tabular}

\section{Conclusions}

We have shown that different ion species mill the same materials at rates that vary significantly and with widely varying texturing artifacts. We have also suggested new applications for novel ion species including material hardening and using oxygen to create curtain-free cuts through organic materials. As our sputter rate database grows with more involvement from the FIB community, it can be used as a resource for researchers who are interested in selecting the proper ion source for their needs.

This initial work to characterize the behavior of novel ion species on different material substrates is the first of many studies planned on the Helios Hydra at CAMCOR. With the onset of novel ion species for FIB, much more work is necessary to understand the strengths and limitations of each species and what new techniques can be developed.

\section{Data Availability}

The data used to support the findings of this study are available within the article.

\section{Conflicts of Interest}

The authors declare that they have no conflicts of interest.

\section{References}

[1] A. Ernst, M. Wei, and M. Aindow, "A comparison of Ga FIB and Xe-plasma FIB of complex Al alloys," Microscopy and Microanalysis, vol. 23, no. S1, p. 288, 2017.

[2] G. Sergey et al., Oxygen Plasma Focused Ion Beam Scanning Electron Microscopy for Biological Samples, 2018, https://www. biorxiv.org/content/10.1101/457820v1.

[3] A. A. Martin, S. Randolph, A. Botman, M. Toth, and I. Aharonovich, "Maskless milling of diamond by a focused oxygen ion beam," Scientific Reports, vol. 5, no. 1, 2015.

[4] V. Brogden, PFIB Sputter Rate Database, 2020, http://camcor. uoregon.edu/fib-mill-database/.

[5] Y. Yamamura and H. Tawara, "Energy dependence OF IONinduced sputtering yields from monatomic solids at normal incidence," Atomic Data and Nuclear Data Tables, vol. 62, no. 2, p. 149, 1996.

[6] L. A. Giannuzzi, R. Geurtz, and J. Ringnalda, "2keV Ga FIB milling for reducing amorphous damage in silicon," Microscopy and Microanalysis, vol. 11, no. S02, 2005.

[7] A. Refke, V. Philipps, E. Vietzke, M. Erdweg, and J. Von Seggern, "Interaction of energetic oxygen with different boron/ carbon materials," Journal of Nuclear Materials, vol. 212-215, pp. 1255-1259, 1994. 